\title{
THE RELATION BETWEEN PLASMA PROTEIN CONTENT, PLASMA SPECIFIC GRAVITY AND EDEMA IN DOGS MAINTAINED ON A PROTEIN INADEQUATE DIET AND IN DOGS RENDERED EDEMA- TOUS BY PLASMAPHERESIS
}

\author{
By A. A. WEECH, C. E. SNELLING,1 AND E. GOETTSCH
}

(From the Department of Pediatrics, Harvard Medical School, Boston, and the Department of Diseases of Children of Columbia University College of Physicians and Surgeons, New York)

(Received for publication September 9, 1932)

Clinical edema of several types and its relation to low serum proteins have been adequately discussed in recent publications $(1,2,3,4,5)$. Experimental edema in animals has resulted from two methods which have in common the lowering of serum protein, that is, plasmapheresis in $\operatorname{dogs}(6,7,8,9,10,11)$, and low protein diets in rats $(12)$ and in the dog (8). The experiments to be discussed in this paper were performed by utilizing both methods of experimental approach. Dogs were maintained on a diet deficient in protein. Edema was produced sometimes acutely by plasmapheresis, sometimes more slowly as the result of dietary deficiency alone, and in several instances after recovery from the edema of plasmapheresis the edema of protein starvation was allowed to supervene in the same animal. Nine dogs have been followed over periods varying from 59 to 107 days and averaging 84 days. It has seemed worthwhile at this time to present together the results of both methods of study and to compare the events attending the onset of edema in both groups of animals and the relationships found for plasma protein concentrations and plasma specific gravity.

\section{METHODS}

The animals were kept in metabolism cages throughout the periods of observation, the daily urine collections being measured and aliquots saved for analysis. The importance of washing the cages to insure complete urine collection was not appreciated at first. Later observations indicated an average loss of 1.9 per cent through neglect of this precaution and accordingly records of total urine have been increased by this amount. Stools were not saved regularly but only over short periods of ten enough to determine approximately the necessary balance corrections. Since the substances studied (sodium, chloride and nitrogen) are excreted chiefly in the urine, these corrections were not large. The diets were offered in weighed amounts and corrected for refusals

${ }^{1}$ National Research Council Fellow. 
when these occurred. Their composition will be given under the section in which nutritional edema is discussed, although all of the dogs were maintained on similar diets. No restriction was placed on water intake. Each dog was weighed at approximately the same time every day, the weights being accurate to at least $0.1 \mathrm{kgm}$., and was examined carefully for evidence of palpable edema. Samples of blood for chemical analysis were obtained by arterial puncture, thus avoiding any effect of stasis, and heparin, $1 \mathrm{mgm}$. per cc., was added to prevent coagulation.

Nitrogen estimations have been made both by macro- and micro-Kjeldahl procedures. Nonprotein nitrogen has been consistently determined by one of the technics which utilize the color developed with Nessler's reagent (13). Nitrogen in protein-containing fractions has been measured by titration. At present we are using, and prefer, a micro-method which depends upon distillation of ammonia in steam into $\mathrm{N} / 70$ hydrochloric acid, the excess acid being titrated with $\mathrm{N} / 70$ alkali, using methyl red as an indicator. ${ }^{2}$ Total plasma protein was calculated as 6.25 times the difference between total and nonprotein nitrogen. Special mention must be made of determinations of the albumin fraction. Removal of globulin with 22.2 per cent sodium sulfate solution, as suggested by Howe (14), was practiced throughout the investigation. The precautions, mentioned by Bruckman, D'Esopo and Peters (15), of maintaining all glassware at incubator temperature and of allowing the precipitated globulins to remain overnight in the incubator before filtration, were incorporated. Albumin was calculated as 6.25 times the difference between the total nitrogen remaining after removal of globulin and nonprotein nitrogen. In most instances results obtained by this procedure have been quite satisfactory, duplicate determinations agreeing within 0.05 gram per 100 cc. Now and again, however, samples of plasma have been encountered in which duplicate determinations have failed to agree. In one instance a discrepancy as large as 0.6 gram per $100 \mathrm{cc}$. was observed. Duplicate determinations on aliquots pipetted from the same filtrate have always agreed; it has, therefore, been apparent that the discrepancies arise in the process of salting out the globulins with sodium sulphate. Furthermore, when the results of such analyses are compared with those obtained on previous and subsequent days, the comparison has always shown the higher of two discrepant results to be closer to the value which would have been expected. This finding suggests that under certain circumstances an appreciable amount of albumin may be precipitated along with globulin by the sodium sulphate. Other observers have had a similar experience (16). As yet no adequate explanation has been found but fortunately the difficulty has arisen only occasionally and then always with samples obtained from one of two dogs. Each of these animals exhibited periods which lasted for several weeks during which the results of albumin analyses were uncertain. In the present communication no conclusions have been drawn which depend on these analyses alone though it has usually been possible to obtain at least reasonable values by performing 4 to 6 parallel determinations and discarding one or several of the obviously low figures. It should, however, be emphasized that determinations of albumin should include duplicate precipitations with sodium sulfate and that no sense of security is justified from a close agreement between aliquots pipetted from the same filtrate.

2 The method utilizes a modified Pregl apparatus which was developed by Dr. M. Heidelberger and Dr. F. E. Kendall of the Department of Medicine of Columbia University. 
Sodium was determined by the method of Butler and Tuthill (17), chloride by the Volhard-Arnold method (18), specific gravity by use of the small weighing bottles described by Moore and Van Slyke (19).

\section{Events attending onset of plasmapheresis edema}

The production of edema in dogs by the method of plasmapheresis has been adequately described by Leiter (6), Barker and Kirk (7) and Shelburne and Egloff (8). In the present investigation the dogs were bled from the femoral artery, the amount withdrawn each time varying from 350-650 cc., and the separated red cells suspended in Locke's solution were reinjected into one of the leg veins. Aseptic precautions were observed. The animals were bled sometimes once, sometimes twice, a day, over periods varying from several days to two weeks. Five dogs have been studied; in four, edema resulted from the procedure; in one, for reasons to be given, edema could not be produced.

In the course of the experiments certain features have been encountered which it has seemed important to hold in mind in attempting to understand or interpret the results obtained. These features may be enumerated as follows:

(1) It became apparent that disagreement among several observers is possible concerning the earliest physical findings to be interpreted as edema. After several days of bleeding one frequently observes that the haunches or groins of an animal have become fuller, that the depth of the femoral artery below the skin, as estimated when making a puncture, has increased. Later a slight imprint may be left by the shank of the needle after it has been pressed against the tissues for some minutes. Such changes are undoubtedly edematous or pre-edematous in nature and yet, at this stage, it may be impossible to demonstrate palpable edema by finger pressure. Finally, and usually quite suddenly, this demonstration becomes possible, first over the dorsa of one or more of the feet, then involving all of the feet and spreading to the toes, ankles, and up the legs. Ascites has not been observed before the appearance of palpable edema, but may develop at any time subsequently. Finally, it should be noted that the amount of edema as judged by physical examination may vary greatly from day to day. With dog B-1, which at one time developed a large collection of fluid in the peritoneal cavity, the appearance of ascites was attended by a great decrease in the palpable edema of the extremities. Chiefly because the early signs of edema or pre-edema appear gradually and insidiously, it has been decided to use the word "edema" only when referring to palpable edema demonstrable by finger pressure.

(2) During a period of active plasmapheresis it is impossible to maintain the plasma proteins at a constant level even for a relatively short period of time. Each operation results in an acute lowering; this is 
followed by rapid replenishment of a part of the removed protein. Whipple and his associates (20) showed that replenishment is particularly rapid during the first fifteen minutes following the operation; we have repeatedly observed that the rise in concentration during the first 24 hours is relatively much greater than that which occurs subsequently. Moreover, the phenomenon assumes greater importance from the circumstance that it is the albumin fraction particularly which shows the greatest rise during the immediate postoperative period. In any event it must be emphasized that the decline in the plasma proteins associated with repeated plasmapheresis and which precedes the development of edema does not take place in the form of a smooth curve but rather as a saw-toothed line with alternate periods of depletion and replenishment. This fact has a twofold significance in attempts to evaluate the protein levels which are associated with the first appearance of edema. When a series of plasmapheresis operations has led to an edematous state and when a period of 24 hours is allowed to elapse before samples of blood are withdrawn for analysis it is possible that the proteins may have regenerated above the correlation level ${ }^{3}$ by the time the samples are obtained, even though they were below the level long enough to permit the appearance of edema. Similarly, when samples are withdrawn shortly after plasmapheresis, analyses may reveal protein concentrations under the correlation level when edema is not present, as the regenerating proteins may have passed the level before sufficient time has elapsed to allow the formation of edema.

(3) The behavior of body weight during plasmapheresis has seemed of great importance. Frequently daily increases have been recorded beginning with the first bleedings. If the volumes of blood exchanged daily are fairly large, the daily increments of added weight become greater, as the experiment is continued, until edema finally results. If bleeding is less vigorous the weight curve may be characterized by instability, i.e., a gain for several days followed by a loss and then later by gains which may or may not continue until edema has appeared. During periods of weight gain the output of urine is suppressed. If at any time the daily operations are interrupted, diuresis with precipitous decline in weight soon occurs. During the period before edema has appeared the decline has always commenced by the day following the omission of bleeding. After edema has developed one or several days may elapse before diuresis sets in (Chart 1). Balance experiments have indicated that the gains in weight are always associated with a retention of both sodium and chloride and that a rapid excretion of both of these substances accompanies the diuresis and weight loss (Table 1).

${ }^{3}$ For reasons, which will appear, the term "correlation level" rather than "critical level" is used throughout this article to refer to plasma protein concentrations below which edema is usually present and above which it is usually absent. 
TABLE 1

Salt balance during plasmapheresis

Dog 589

\begin{tabular}{|c|c|c|c|c|}
\hline Day & $\begin{array}{l}\text { Plasmapheresis } \\
\text { exchange }\end{array}$ & Change in weight & Sodium balance & Chloride balance \\
\hline $\begin{array}{r}1 \\
2 \\
3 \\
4 \\
5 \\
6 \\
7 \\
8 \\
9 \\
10 \\
11 \\
12 \\
13 \\
14 \\
15 \\
16 \\
17 \\
18 \\
19 \\
20\end{array}$ & $\begin{array}{c}c c . \\
645 \text { and } 565 \\
510 \text { and } 605 \\
560 \text { and } 610 \\
625 \\
630 \text { and } 610 \\
\text { None } \\
475 \\
570 \\
660 \\
625 \\
465 \\
480 \\
\text { None } \\
\text { None } \\
\text { None } \\
\text { None } \\
\text { None } \\
\text { None } \\
\text { None } \\
\text { None }\end{array}$ & $\begin{array}{l}\text { grams } \\
+450 \\
+150 \\
+400 \\
+800 \\
+800 \\
-2000 \\
-250 \\
-150 \\
-200 \\
+800 \\
+300 \\
+500 \\
+300 \\
-550 \\
-850 \\
-\quad 900 \\
-\quad 600 \\
-\quad 250 \\
-\quad 50 \\
-\quad 150\end{array}$ & $\begin{array}{l}m m . \\
+41 \\
+57 \\
+91 \\
-40 \\
-129 \\
-41 \\
-16 \\
+3 \\
+115 \\
+12 \\
+19 \\
+20 \\
-57 \\
-7 \\
-32 \\
-77 \\
+27 \\
-30 \\
+24\end{array}$ & $\begin{array}{l}m m . \\
+41 \\
+51 \\
+99 \\
-56 \\
-103 \\
-23 \\
-10 \\
+19 \\
+110 \\
+42 \\
+33 \\
+46 \\
-26 \\
+8 \\
-30 \\
-63 \\
+21 \\
\overline{+} 36 \\
+13\end{array}$ \\
\hline
\end{tabular}

Emphasis must be placed on the fact that the weight gains associated with the first plasmapheresis operations of ten take place before the plasma proteins have been greatly lowered. All findings indicate that they are due to salt and water retention but there is no evidence to indicate that the retention begins when the proteins have been lowered to any particular concentration. As will be shown later a close correlation does exist between plasma albumin concentration and palpable edema but at present it seems that palpable edema and not water retention per se must form the basis of the correlation.

(4) The results obtained in these experiments are in agreement with those reported by other investigators in indicating that salt is essential for the formation of plasmapheresis edema. Leiter (6) stated that "no edema is possible without an endogenous or exogenous supply of the chief constituents of edema fluid." Fahr, Kerkhof and Giere (10) showed that only slight edema resulted from vigorous plasmapheresis until a daily intake of $1500 \mathrm{cc}$. of tap water was replaced by the same volume of 0.9 per cent salt solution. Following the replacement "the output of urine immediately fell far below the intake and massive edema and ascites appeared." In the experiments being reported the diets were so planned as to furnish a salt intake adequate for fairly rapid edema formation. Dog 448, however, refused to eat after the first few days of experimenta- 
tion and all attempts to administer food or salts by gavage led to vomiting. As a result of daily bleedings the plasma albumin was depleted to 0.9 gram per $100 \mathrm{cc}$. and yet the animal lost weight steadily and no edema appeared. With dog B-2, after plasmapheresis had been carried to the

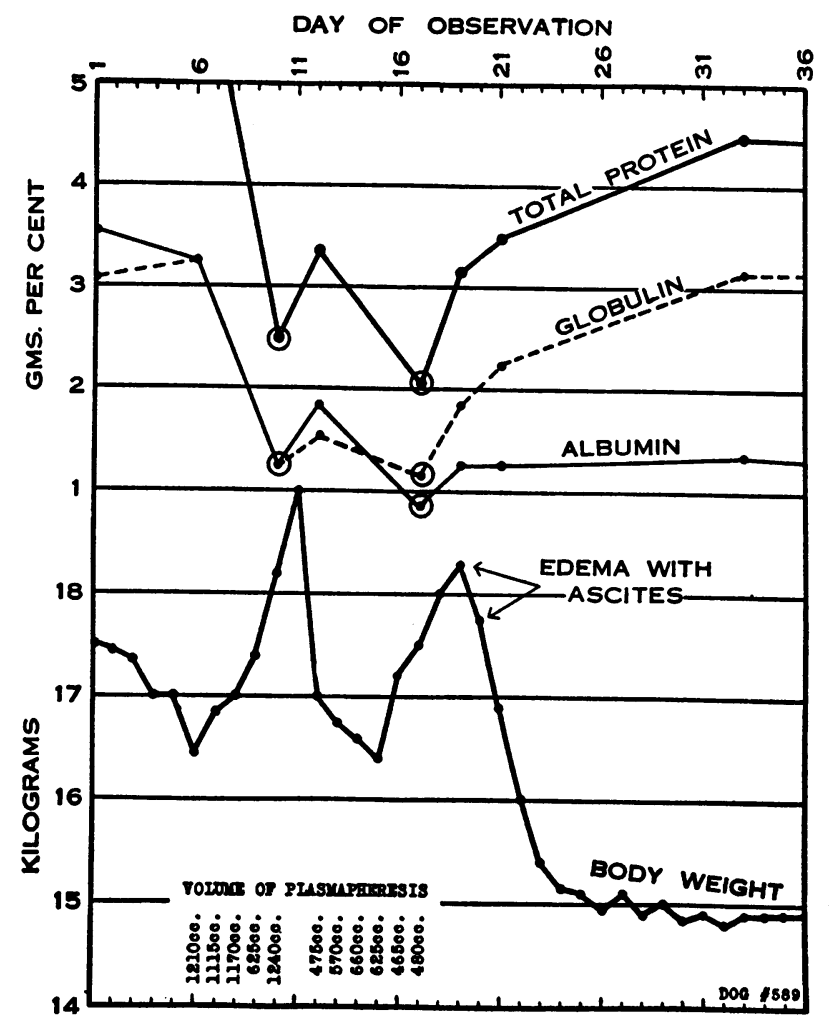

Chart 1. Changes in Plasma Proteins and Body Weight Accompanying Plasmapheresis.

Blood samples for analysis were usually withdrawn 24 hours or more following operation. The encircled points refer to samples obtained within 20 minutes of the completion of a blood exchange.

point of producing a slight edema, all sodium salts in the diet were replaced by equivalent amounts of potassium salts, and the bleedings continued. During this period the weight was stationary and edema did not increase. Then, when plasmapheresis was interrupted and sodium salts returned to the diet, the weight and edema at once increased in spite of a rising plasma protein concentration.

To summarize the features attending the onset of plasmapheresis edema: Each bleeding results in an acute fall in the plasma protein concentration which is followed by a period of replenishment which lasts 
until the next bleeding causes another acute fall. The curve representing the progress of protein depletion, therefore, is not smooth but more in the nature of a saw-toothed line with alternate periods of depletion and regeneration. Gains in weight due to retention of salt and water may occur before the proteins have been greatly lowered. Such gains are promptly lost if bleeding is interrupted. Later when edema has made its appearance one or more days may elapse before diuresis follows cessation of bleeding. Palpable edema is preceded by a stage of pre-edematous fullness of various tissues. An adequate supply of sodium chloride is essential for the formation of this form of edema.

\section{Events attending onset of nutritional edema}

Circumstances and diets which lead to nutritional edema in the human have been described by various authors $(21,22)$. Denton and Kohman (23), Maver (22), Kohman (24), and Frisch, Mendel and Peters (12) have shown that young rats fed on diets composed chiefly of carrots in many instances gradually develop edema. Kohman showed that insufficient protein is the factor responsible for the edema in these animals and Frisch, Mendel and Peters correlated the edema with low serum protein. Shelburne and Egloff (8) reported the production of low serum protein edema in a dog maintained on a diet composed of potato, cream, turnip, butter and lactose. The experiments described in this paper were begun with an attempt to use so-called synthetic diets which were composed of corn starch, butter fat, sugar, yeast and a mixture of essential salts. They were similar to those employed by Gamble and his associates (25) in the feeding of rats and contained no protein other than that present in the yeast which was added as a source of vitamin. Dogs B-1 and B-2 received this diet exclusively. Plasmapheresis edema was produced initially in both of these animals; B-2 finally developed nutritional edema which remained when plasmapheresis was discontinued. Dogs $430,448,449,451$ and 589 were started on the same diet and later changed to a natural food diet to be described presently. Dogs 451 and 589 exhibited both plasmapheresis edema and nutritional edema at different stages. Plasmapheresis was not practiced with dogs 430 and 449 and these animals developed only nutritional edema. As already mentioned dog 448 never became edematous. Finally, dogs 565 and 597 were fed from the start on the natural food diet and both developed edema.

Synthetic diets were finally abandoned because the majority of animals exhibited periodic attacks of diarrhea, a state which interfered with collection of excreta. Attempts to control the diarrhea by adding agar agar or charcoal or varying the composition of the salt mixture were unsuccessful. The composition of the natural food diet follows: 


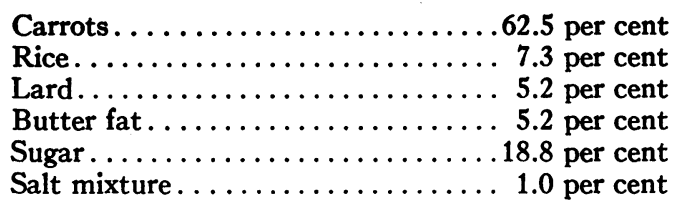

One hundred grams of this diet contain 1.27 gram of protein and furnish about 225 calories. It was offered in amounts which provided approximately 67 calories per kilogram of body weight. Water was added as necessary for satisfactory cooking. Additional weighed quantities of sodium chloride were incorporated, usually 5 grams per day, to insure adequate material for edema formation. The use of this diet eliminated diarrhea; refusals occurred only in the last stages of malnutrition.

In addition to edema animals fed on this diet developed a seborrheic form of dermatitis and sometimes leg ulcers. The first evidence of dermatitis sometimes appeared before edema; ulcers, when they occurred, followed some weeks later. The presence of skin lesions has brought up the question of whether the diet might be deficient in vitamins in addition to protein. Carrots are known to contain all the vitamins but whether the quantities offered were sufficient for optimum maintenance of adult dogs is open to question. It would seem, however, that the addition of 5 per cent butter fat would exclude the possibility of A or D deficiency. Moreover, dogs are supposed not to require vitamin $\mathrm{C}$ and the absence of any diminution in appetite before the terminal stages of malnutrition would seem to rule out B deficiency. Furthermore, the symptoms presented by the animals in no way suggested the acute disease "blacktongue" in dogs which is supposed to be the expression of G deficiency (26).

Experience has shown that dogs maintained on the natural food diet exhibit a negative nitrogen balance, the loss in the animals studied approximating one gram of nitrogen per day. As a result of the negative balance the serum albumin concentration declines, at first rather rapidly, and, then, over a period of weeks, very gradually. Finally in the terminal stages it may again fall rapidly. The plasma globulin concentration has usually declined during the first week or two; sooner or later, however, it begins to rise and usually exceeds the level initially present. Finally in the last stages it may again decrease. Total protein decreases rapidly for several weeks, then remains constant or very slowly declines for many weeks and at the end again falls rapidly. After an interval, which in the four dogs treated by diet alone varied from 35 to 55 days and averaged 45 days, edema appears. The edema has usually been demonstrable first over the dorsa of the hind feet but sometimes over the dorsa of all four feet simultaneously. Within a few days the soft tissues about the Achilles tendons of the hind legs become swollen and pit with pressure. 
Gradually the edema increases, spreading up the legs and down the feet to involve the toes. As a result of edema of the toes the claws are spread widely apart and come to stand upward at an angle from the feet instead of curving downward. Ascites has not been demonstrable clinically, but in one instance $200 \mathrm{cc}$. of fluid were removed from the peritoneal cavity at autopsy.

The behavior of the weight curve before and after the appearance of edema has been interesting. With human nutritional edema it has been stated (Bürger) that intelligent patients first notice a rapid increase in body weight preceding the development of edema. With the dogs studied in this investigation no such increase has been apparent. They have all exhibited a more or less gradually declining weight and the rate of decline has been singularly free from major variations either just before or at the time of the appearance of edema. This is illustrated in

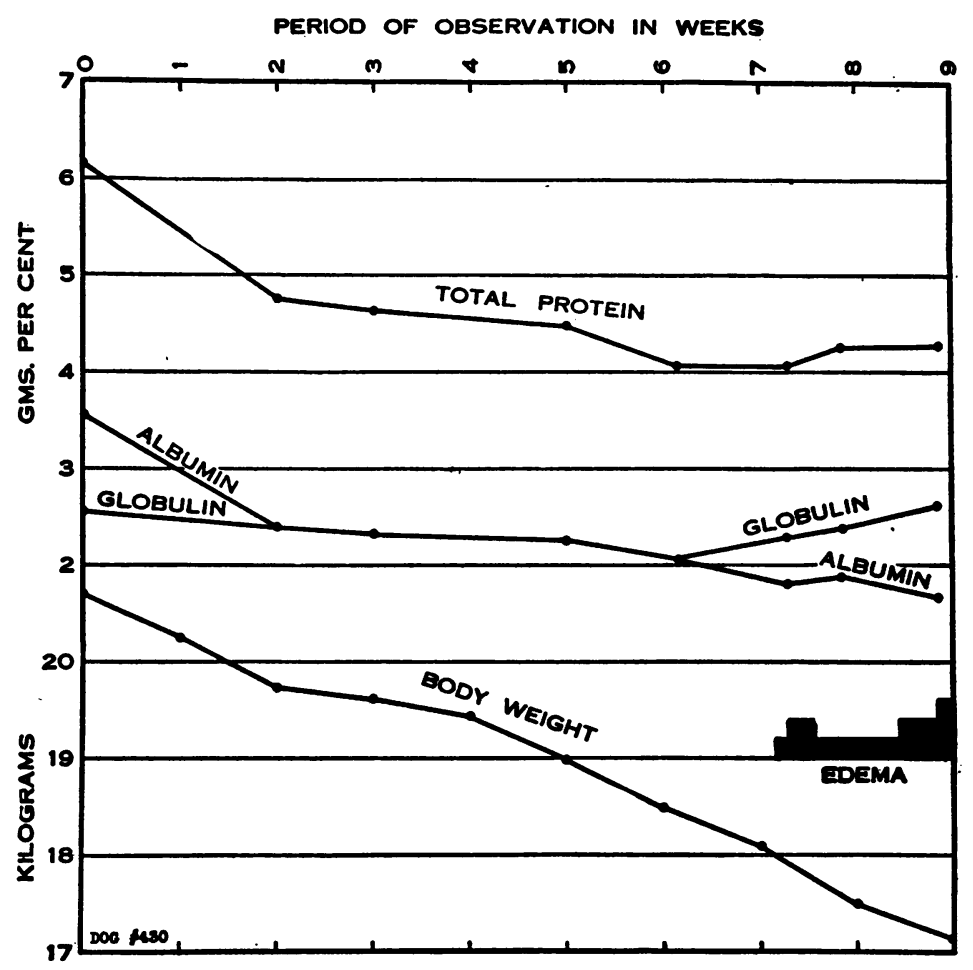

Chart 2. Events Attending the Onset of Nutritional Edema

The slope of the weight curve is essentially unaltered throughout the period of observation.

Charts $\mathbf{2}$ and $\mathbf{3}$ in which weekly weights only are given and daily fluctuations arising from incomplete emptying of bladder or bowel flattened by charting as the weekly weight the average of the weight measured on that 
day and the weights of two previous and two subsequent days. Similar weight charts have been obtained with all animals which developed nutritional edema. They furnish no evidence concerning the existence of a definite serum albumin level at which water retention begins; at least

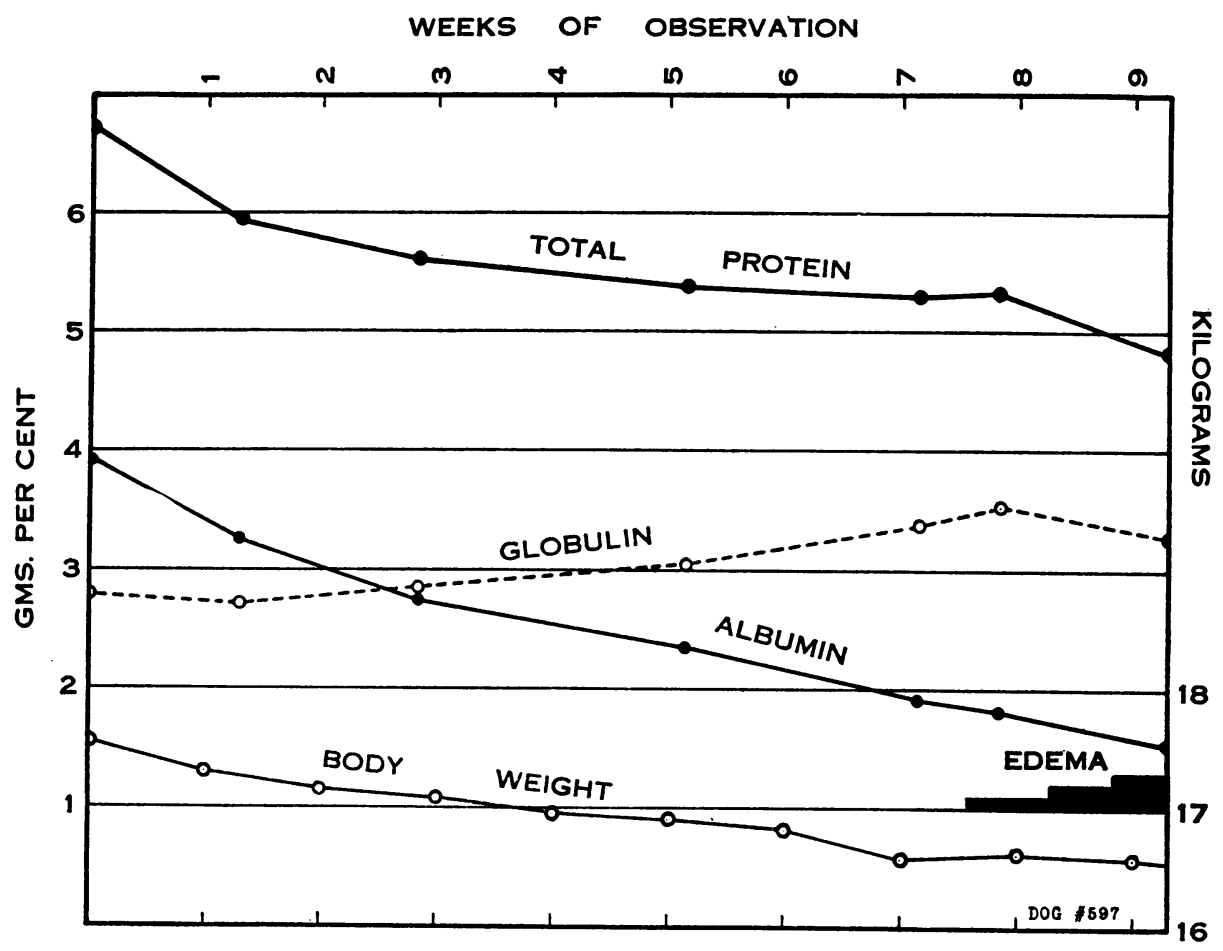

Chart 3. Events Attending the Onset of Nutritional Edema

this is true if one is permitted to expect a gain in weight to result from water retention. Rather the impression is gained that, if water retention is essential for edema formation, the retention takes place in small amounts distributed throughout the entire experimental period, keeping step, as it were, with the declining plasma proteins and finally reaching such a degree as to manifest itself as palpable edema.

The above impression, based on an examination of weight curves, is strengthened by studies of salt balance during the period preceding nutritional edema. Several experiments were complicated by unsuccessful attempts to precipitate edema prematurely through the administration of large quantities of sodium chloride or sodium bicarbonate and are, therefore, not satisfactory for simple balance studies. Dog 597, however, received a constant intake of 124 millimols sodium and 118 millimols chloride daily throughout the experimental period. The results of a balance study are shown in Table 2. Although a small 
TABLE 2

Salt balance during development of nutritional edema Dog 597

\begin{tabular}{c|c|c|c|c}
\hline \hline $\begin{array}{c}\text { Period } \\
\text { (6 days each) }\end{array}$ & $\begin{array}{c}\text { Sodium balance } \\
\text { per day }\end{array}$ & $\begin{array}{c}\text { Chloride balance } \\
\text { per day }\end{array}$ & $\begin{array}{c}\text { Plasma albumin } \\
\text { concentration }\end{array}$ & Remarks \\
\cline { 2 - 4 } 1 & $m$. mols & $\begin{array}{c}m . \text { mols } \\
\text { grams per cent }\end{array}$ & \multirow{2}{*}{ Diet started * } \\
2 & +4 & +6 & 3.92 & \\
3 & +7 & +2 & 3.25 & \\
4 & -8 & -6 & & \\
5 & +2 & +2 & 2.86 & \\
6 & +2 & +1 & & \\
7 & -3 & +4 & & \\
8 & +7 & +5 & 2.35 & \\
9 & +6 & 0 & & \\
10 & +2 & +1 & 1.92 & \multirow{2}{*}{ Edema appeared } \\
11 & +4 & +5 & 1.81 & \\
\hline
\end{tabular}

* Sodium intake $=124$ millimols per day.

Chloride intake $=118$ millimols per day.

retention of both sodium and chloride ions is indicated throughout the entire period of low protein feeding, this fact cannot be stressed as the positive balances were small and probably within the limits of error involved in collecting and analyzing specimens. The significant point, however, is that the balance remained essentially the same throughout and that the appearance of edema was not preceded by a period of unusually rapid salt retention. Furthermore, the fact that edema did develop argues in favor of a positive salt balance even though the uncertainty attending the measurement of small retentions in metabolism experiments may leave this point unsettled. It is nevertheless conceivable that endogenous salt liberated and retained in the course of progressive malnutrition may be sufficient for eventual edema formation even though salt metabolism experiments indicate that the animal is in balance.

The implication of the above experiments that minimum salt retentions over long periods of time may lead to edema prompted us to omit all added salt, including the salt mixture, from the diet of dog 565 . This animal ingested only the salts naturally present in the food substances used (17 millimols sodium and 4 millimols chloride daily). Edema appeared on the 40 th day, ${ }^{4}$ five days sooner than the average time required for all of the dogs and, quite surprisingly, the appearance was associated with a higher serum albumin concentration (2.17 grams per

4 Although at the time of its first appearance the edema was quite like that observed in the other animals, it did not advance as rapidly as in the dogs receiving abundant salt and, until death, remained limited to the most dependent parts, - the ankles and feet. The latter, however, were markedly swollen. 
$100 \mathrm{cc}$.) than had previously been observed in association with edema. The experiment has as yet not been confirmed, but for the present may be regarded as supporting the contention that edema may result from small salt retentions over a number of days rather than from an acute retention following a depletion of the proteins below some definite level.

Finally, the figures for nitrogen balance have been examined for evidence of water retention. If it is assumed that a negative nitrogen balance of one gram corresponds to the catabolism of 6.25 grams of tissue protein and that each gram of protein in breaking down liberates 3.25 grams of water, ${ }^{5}$ it is possible to calculate from the known nitrogen elimination the loss of weight which would have occurred if all products of catabolism were excreted. If the calculated loss should turn out to be greater than the observed loss, the result would suggest water retention. The dogs studied in these experiments all exhibited a progressive decline in weight which was assumed to result from a loss of both nitrogen and fat. Neither the total calories fed nor the condition of the animals at autopsy has suggested the possibility of fat storage. In most instances the loss of weight has been greater than could be accounted for by nitrogen elimination and must have been due to considerable additional

TABLE 3

Minimum water retention calculated from negative nitrogen balance Dog 597

\begin{tabular}{c|c|c|c|c|c|c}
\hline \hline $\begin{array}{c}\text { Period } \\
\text { (6 days each) }\end{array}$ & $\begin{array}{c}\text { Loss of } \\
\text { weight }\end{array}$ & $\begin{array}{c}\text { Loss of } \\
\text { nitrogen }\end{array}$ & $\begin{array}{c}\text { Protein } \\
\text { catabolism }\end{array}$ & $\begin{array}{c}\text { Water } \\
\text { freed }\end{array}$ & $\begin{array}{c}\text { Calculated } \\
\text { weight loss }\end{array}$ & $\begin{array}{c}\text { Calculated } \\
\text { water retained }\end{array}$ \\
\cline { 2 - 6 } 1 & grams & grams & grams & grams & grams & grams \\
2 & 170 & 7.7 & 48 & 156 & 204 & 34 \\
3 & 140 & 6.5 & 41 & 133 & 174 & 34 \\
4 & 60 & 4.9 & 31 & 101 & 132 & 72 \\
5 & 130 & 5.5 & 34 & 111 & 145 & 15 \\
6 & -350 & 5.1 & 32 & 104 & 136 & 486 \\
7 & 510 & 4.8 & 30 & 98 & 128 & -382 \\
& -40 & 5.3 & 33 & 107 & 140 & 180 \\
\hline
\end{tabular}

Edema first demonstrable 9 days after end of seventh period.

Calculated water retained during 7 periods (42 days) $=439$ grams.

fat destruction. With dog 597 the weight decline was very gradual and a comparison of observed weight loss with that calculated from nitrogen elimination (Table 3) does indicate water retention from the beginning of the experiment. This water retention has been entered in the table as "minimum" because of the belief that a knowledge of fat catabolism

${ }^{5}$ The figure 3.25 was obtained by calculating the average relation between protein and water in a large number of analyses of lean meat taken from the tables of Atwater and Bryant (U. S. Dept. of Agriculture, Bulletin No. 28). It agrees satisfactorily with the figures 3.59 and 3.00 , used for a similar calculation by Gamble, Ross and Tisdall (J. Biol. Chem., 1923, lvii, 633) and by Newburgh and Johnston (J. Clin. Invest., 1930, viii, 197), respectively. 
would account for part of the weight lost and increase the values assigned to retained water.

In summary of the events attending the onset of nutritional edema: A diet which produces a negative nitrogen balance leads to progressive decline in the plasma albumin concentration, which, because of a tendency for globulin to rise, is not reflected by changes in the total protein. After a variable interval edema develops. Body weight declines gradually throughout the experimental period and does not increase rapidly during the days preceding the appearance of edema. The behavior of the weight curve suggests a gradual progressive retention of water throughout the experiment and gives no evidence of a rapid retention following depletion of the plasma protein below some definite level. Studies of salt metabolism and nitrogen balance furnish additional evidence in favor of progressive gradual retention of salt and water.

\section{Relation between palpable edema and plasma proteins}

In this section a correlation is to be drawn between plasma protein concentration and clinical edema, the latter being defined as a state of the tissues in which pitting is demonstrable by finger pressure. The collected data are summarized in Chart 4. The results of plasmapheresis and
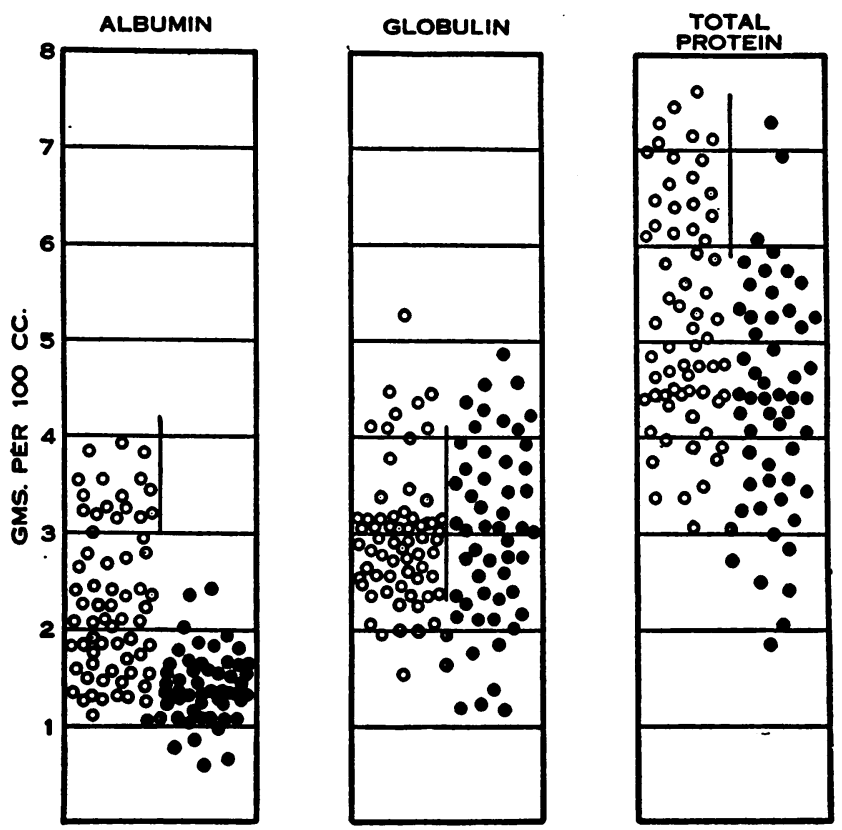

Chart 4. The Relation between Plasma Protein Concentration and Edema in Dogs

Open circles indicate estimations made when no edema was present; black circles indicate estimations made when edema was present; vertical lines in the middle of each column indicate the range of normal variation in the authors' experience. 
simple nutrition experiments are included in the same chart as the combination serves to emphasize the important fact that a close correlation with edema exists only in the albumin fraction of the plasma proteins. Plasmapheresis results in a lowering of both albumin and globulin, protein starvation leads to low albumin but abnormally high globulin values, and yet both result in edema. It is clear that globulin must play at least only a minor rôle in regulating water distribution. With albumin it is seen that the majority of figures indicate a correlation level between 1 and 2 grams per $100 \mathrm{cc}$. With one animal only edema appeared with an albumin concentration higher than 2 grams per cent $(2.17$ grams per $100 \mathrm{cc}$.). A few higher values appear in the chart. These were all secured with one animal (449) when an attempt was made to remove edema by feeding a high protein diet. An explanation for the high values will be given presently.
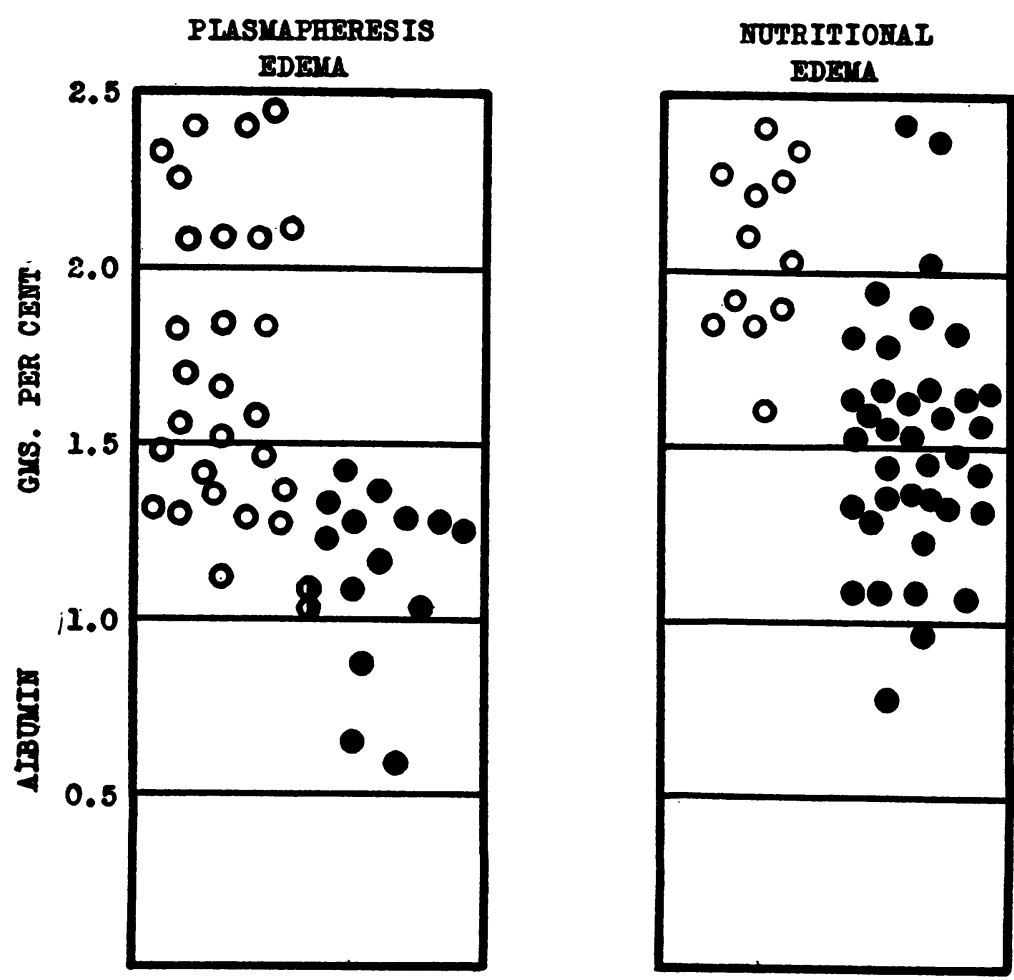

Chart 5. Comparison of the Plasma Albumin Correlation levels in Plasmapheresis Edema and Nutritional Edema

In Chart 5 the pertinent albumin values have been recharted and distributed in plasmapheresis and nutritional groups. The chart discloses that the correlation levels are not identical in the two groups of 
animals. With plasmapheresis edema the zone is definitely between 1.0 and 1.5 gram per $100 \mathrm{cc}$. and with nutritional edema the majority of figures are between 1.5 and 2.0 grams per $100 \mathrm{cc}$. The difference is perhaps more clearly brought out in Table 4 , in which is entered the albumin concentration, for each dog who developed plasmapheresis edema, at which diuresis and loss of edema occurred, and, in the case of the protein-starved animals the albumin concentration at which edema was first observed. It will be noted that this method of selection yields plasmapheresis values somewhat above and nutritional values somewhat below the correlation level. Nevertheless, a distinct difference between the two groups is still apparent. That the difference does not result from chance selection of animals is illustrated in the case of dog 589 which eliminated the edema of plasmapheresis at an albumin concentration of 1.26 gram per $100 \mathrm{cc}$. and later developed nutritional edema at a concentration of 1.63 gram per $100 \mathrm{cc}$. The other animals (B-2, 451) which developed nutritional edema following plasmapheresis edema did not show sufficient albumin regeneration after cessation of bleeding to make a comparison of this type possible but with dog 589 the plasma proteins were purposely raised by transfusion after the disappearance of plasmapheresis edema in order to observe this very point.

TABLE 4

Relation between edema and plasma albumin concentration

\begin{tabular}{|c|c|c|c|}
\hline \multicolumn{2}{|c|}{ Plasmapheresis } & \multicolumn{2}{|c|}{ Nutritional } \\
\hline Dog & Concentration & Dog & Concentration \\
\hline $\begin{array}{l}\text { B-1 } \ldots \ldots \ldots \ldots \\
\text { B-2 } 2 \ldots \ldots \ldots \ldots \ldots \\
451 \ldots \ldots \ldots \\
589 \ldots \ldots \ldots \ldots\end{array}$ & $\begin{array}{c}\text { grams per cent } \\
1.35 \\
1.11 \\
1.30 \\
1.26\end{array}$ & $\begin{array}{l}430 \\
449 \\
597 \\
589 \\
565\end{array}$ & $\begin{array}{c}\text { grams per cent } \\
1.79 \\
1.59 \\
1.81 \\
1.63 \\
2.17\end{array}$ \\
\hline
\end{tabular}

TABLE 5

Protein content of edema fluids

\begin{tabular}{|c|c|c|c|c|c|}
\hline Dog & Nature of fluid & Protein & Dog & Nature of fluid & Protein \\
\hline $\begin{array}{l}597 \\
597 \\
597 \\
451 \\
449 \\
449 \\
449\end{array}$ & $\begin{array}{l}\text { Subcutaneous } \\
\text { Subcutaneous } \\
\text { Subcutaneous } \\
\text { Subcutaneous } \\
\text { Subcutaneous } \\
\text { Subcutaneous } \\
\text { Subcutaneous }\end{array}$ & $\begin{array}{c}\text { grams per cent } \\
0.28 \\
0.10 \\
0.16 \\
0.34^{*} \\
1.01 \\
0.90 \\
1.10\end{array}$ & $\begin{array}{l}565 \\
589 \\
589 \\
589 \\
449 \\
589\end{array}$ & $\begin{array}{l}\text { Subcutaneous } \\
\text { Subcutaneous } \\
\text { Subcutaneous } \\
\text { Peritoneal } \\
\text { Peritoneal } \\
\text { Pleural }\end{array}$ & $\begin{array}{c}\text { grams per cent } \\
0.28 \\
0.28 \\
0.21 \\
0.72^{*} \\
2.95^{*} \\
0.55^{*}\end{array}$ \\
\hline
\end{tabular}

* Analysis of specimen secured at autopsy. 
The discrepancy between the correlation levels has stimulated an interest in the types of edema occurring in the two groups of animals. The protein content of the nutritional edema fluids examined to date is shown in Table 5. With the exception of observations on dog 449, the subcutaneous edema fluids show protein concentrations varying between 0.10 and 0.34 gram per cent. These may be compared with variations between 0.01 and 0.25 gram per cent observed by Leiter in plasmapheresis edema. On the whole the figures suggest a slightly higher edema fluid protein content for nutritional than for plasmapheresis edema but the discrepancy seems scarcely great enough to account for the different correlation levels. Why dog 449 should have exhibited such a high level of edema fluid protein is not known but it may be noted that the observations were made late in the experimental period after high protein feeding had been instituted in an attempt to promote recovery, that they speak for an altered capillary permeability, and that they account for the high plasma albumin values measured with this dog before edema disappeared.

Relation of plasma specific gravity to total plasma protein and to occurrence of edema

Moore and Van Slyke (19) have pointed out a close relationship between the total protein of plasma and its specific gravity. This relationship is expressed by the following formula:

Total protein $=($ Specific gravity -1.007$) 343$.

The equation is that of a straight line which can be charted with specific gravity as abscissa and total protein as ordinate.

Estimations of specific gravity during the course of these experiments have afforded an opportunity for verifying the above equation and of demonstrating its applicability to canine plasma. The data are presented graphically in Chart 6 . In studying human subjects Moore and Van Slyke did not encounter plasmas whose specific gravity was lower than 1.018. In the present work with dogs a number of measurements were made of gravities considerably lower than this. The lowest recorded was 1.0121 , the total protein by Kjeldahl being 1.84 gram per $100 \mathrm{cc}$. It will be seen from Chart 6 that the equation of Moore and Van Slyke holds for plasmas whose specific gravity and protein content are as low as have been observed. The chart also demonstrates the lack of any close correlation between specific gravity and edema.

\section{DISCUSSION}

In 1896 Starling (27) demonstrated the rôle of the colloid osmotic pressure of the plasma protein in counterbalancing the effect of mechanical pressure within the capillaries and in causing the absorption of salt solution injected into the subcutaneous tissues. The importance of these 


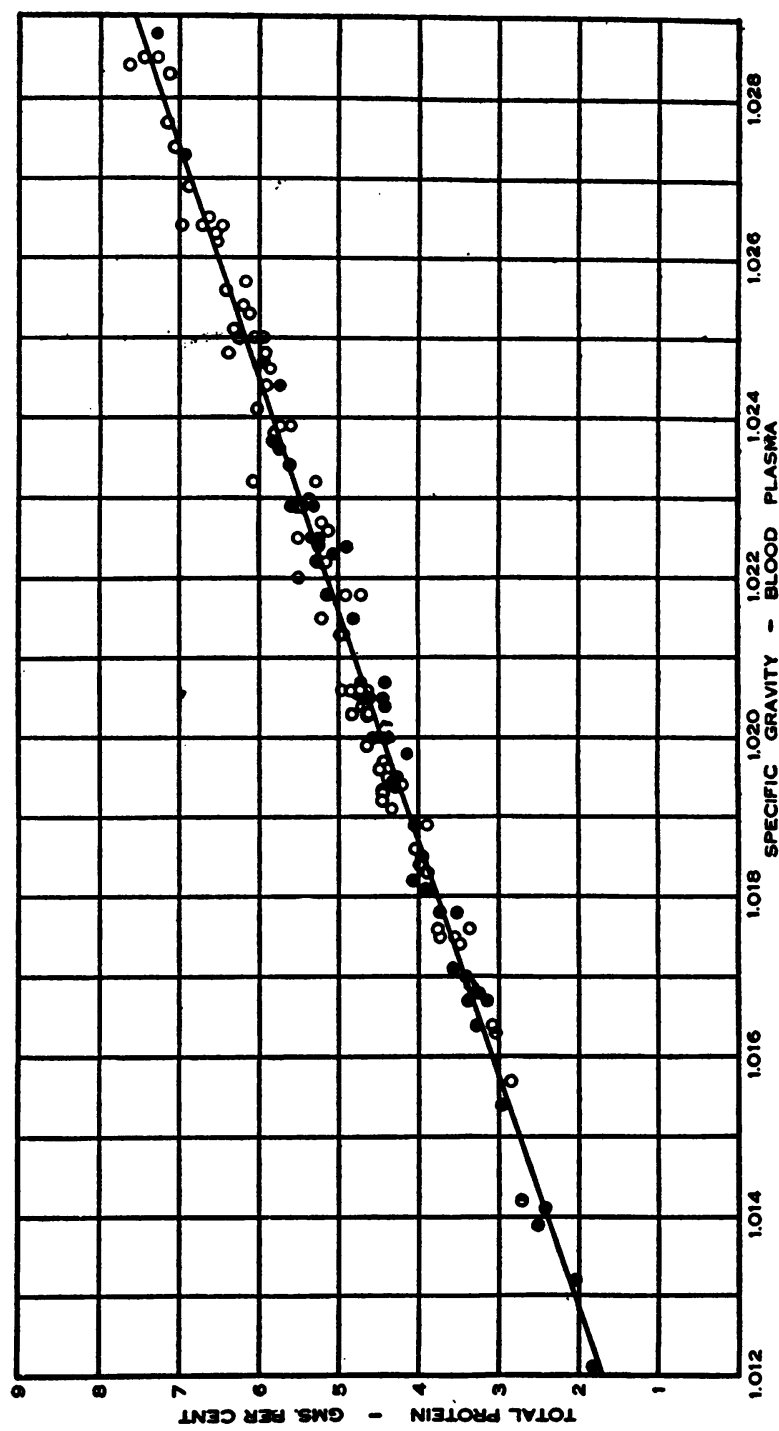

ำ

z

药

응

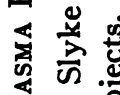

ค. 동

눈

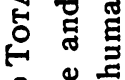

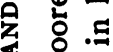

$<\sum \infty$

悹宁

댕 턴

บ

胥

品至 总

ङ 탱도

ค 5

z

四 貌

ह 동

四 远

응 导

实

狊

م $\stackrel{\frac{\pi}{60}}{0}$

b 离

范

遅 
two factors, capillary blood pressure and plasma oncotic pressure, in regulating water distribution between blood vessels and intercellular spaces, is now widely recognized. Moreover, it is generally assumed, and some data exist to support the view (3), that in health the oncotic pressure is greater than the mean capillary pressure and that because of this "any excess of fluid in the tissue spaces will become absorbed" (Krogh). The discrepancy between the forces of oncotic pressure and capillary pressure is referred to by Krogh, Landis and Turner (28) as a "margin of safety" and its existence is implied by the expression "critical level" which has been widely used and which suggests a sudden transition point where oncotic pressure becomes less than capillary pressure and fluid and salts with equal suddenness begin to migrate toward the interstitial spaces. Krogh and his associates seem to have shown that a small margin of safety does exist when the pressure within the capillaries is slowly increased by the application of a "pressure plethysmograph." It should be noted, however, that the instrument itself when fastened to the arm produced a venous pressure between 12 and $14 \mathrm{~cm}$. water and that the average pressure at which filtration began was only $17 \mathrm{~cm}$. water. The margin of safety was, therefore, small. Moreover, the increase in arm volume was studied only over half-hour periods and it is conceivable that pressures even lower than $17 \mathrm{~cm}$. might have occasioned measurable increments if applied for longer periods of time.

From what has been said in the preceding sections it is clear that the correlation between plasma albumin concentration and edema does not relate to a definite protein concentration which exists at the moment a "margin of safety" has been exceeded and at which retention of salt and water begins but that it pertains only to the concentration first found in association with clinical edema, a degree of interstitial fluid accumulation great enough to permit detection by palpation. Therefore, the term "correlation level" rather than "critical level" has been used throughout this paper. The manner in which salt and water are retained, namely, in successive increments over a time which apparently embraces the entire period of plasma albumin depletion, suggests the presence of an equilibrium between plasma proteins and the volume of fluid in the interstitial spaces. The equilibrium seems to be maintained throughout the entire range of protein variation in such a way that every slight protein decline leads to a correspondingly slight increase in interstitial fluid. Such an equilibrium, if substantiated, is of some importance as it directs attention to the factors responsible for its existence and it is evident that at least one of these factors, namely, the one which prevents either unlimited passage of fluid into the interstitial spaces or unrestrained withdrawal of this fluid, must reside within the tissues themselves.

The idea that forces arising in the tissues may be important in regulating fluid distribution is not new. In 1884 Landerer (29) developed his 
notion of the rôle of tissue elasticity or tension in counterbalancing blood pressure within the capillaries. Starling (27) showed that back-pressure from the tissues could not alone compensate for intracapillary blood pressure inasmuch as tissue pressures great enough to effect such compensation led to collapse of the veins and thereby promoted further filtration into the tissues rather than absorption. The concept of equilibratory forces residing in the intercellular spaces has been revived and elaborated by Schade (30), who claims the existence of two opposing factors,-(1) tissue tension or elasticity (Gewebspannung) and (2) imbibition pressure of interstitial colloids (extracelluläre wasserdurchtränkte Bindegewebskolloid). As an accessory force the first factor will be generally accepted although according to Krogh (3) it becomes significant only when the tissues have been appreciably distended with edema fluid. Regarding the second factor it is sufficient for present purposes to note that interstitial fluid contains at least some protein and that other colloid, if such exists in the intercellular spaces, must be in osmotic equilibrium with this fluid. The quantity of protein in the interstitial fluid has been measured and is low in filtration edema; the amount in normal interstitial fluid is not known and the magnitude of its oncotic pressure cannot be estimated. It is clear, however, that the balance between intracapillary blood pressure and oncotic pressure must be complicated by forces outside the capillary walls. The effective oncotic pressure must be the difference between serum oncotic pressure $(S)$ and the oncotic pressure of the interstitial fluid $(I)$. This fact has been stressed by Field and Drinker (31). The effective mechanical pressure must be the difference between capillary blood pressure $(C)$ and elastic back-tension from the tissues $(T)$. Under stationary conditions, that is, at times when edema is neither forming nor receding, these forces may be assumed to be in a state of equilibrium which is expressed by the equation:

$$
S-I=C-T \text {. }
$$

The equation is similar to one employed by Iversen and Johansen (32) in discussing the forces concerned in the production of ascites and pleural effusion. It should be noted that not only is the value of $S$ .decreased by that of $I$ but also that the converse is true, namely, the ability of $I$ to attract fluid is limited by the value of $S$. Consequently, if the equilibrium is disturbed by a fall in serum oncotic pressure $(S)$, the proteins of the interstitial fluid will be able to attract more water, will be diluted by the process and their oncotic pressure $(I)$ correspondingly decreased. The increased quantity of interstitial fluid, by producing an increase in mechanical tissue tension $(T)$, will result, after an interval, in a new equilibrium. Moreover, it is interesting to note that under normal conditions, when $T$ is small, the volume of fluid in the intercellular 
spaces must be controlled chiefly by the oncotic pressure of the interstitial fluid and, conversely, that in the edematous state, which is known to be associated with a low value of $I$, the volume of interstitial fluid is limited by the increased value of $T$.

The concept outlined above of a constant equilibrium between forces on both sides of the capillary wall is in harmony with the experimental results of this investigation. It presupposes the existence of a relation at all times between serum oncotic pressure and the volume of interstitial fluid and affords a rational explanation of the observed manner of water retention when the plasma proteins are progressively lowered. It is evident, however, that events are not as simple as those outlined. Field and Drinker (33) have shown that the acute plasma protein depletion of plasmapheresis is accompanied by an increased lymph flow. Knowledge of the forces involved in maintaining lymph circulation is as yet fragmentary but it is clear that they may modify the above simple relation between intra- and extravascular pressures. Apparently, however, the modification consists in the addition of a dynamic phase to an equilibrium which would otherwise be static and does not obscure the effect of factors controlling the static phase.

Thus far, no explanation has been offered for the different correlation levels found in plasmapheresis and nutritional edemas. Analyses of edema fluid from the two groups of animals were compared with the thought that the fluids obtained from dogs treated by diet alone might contain more protein than was present in fluids from plasmapheresis edema. A difference, if found, would have argued in favor of an alteration in the permeability of the capillary walls resulting from prolonged maintenance on the protein-deficient diet. Actually average figures from the two groups did indicate a small difference of this nature but because the difference was small and more especially because there was some overlapping in the results of individual analyses, the argument could not be supported with the analytical data obtained. The data do not, however, furnish conclusive evidence that the different correlation levels are not due to alteration in capillary permeability as it is conceivable that the change might be of such a nature and degree as to permit selective filtration of the smallest and osmotically most active protein molecules and that the effective plasma oncotic pressure might, therefore, be significantly reduced without a proportionate increase in protein nitrogen in the edema fluid. Direct measurements of the oncotic pressure of edema fluids, which will be required to evaluate this possibility, have as yet not been attempted. Be this as it may, another possible explanation of the different correlation levels has presented itself. It is a matter of common observation that the subcutaneous tissues of malnourished persons, and particularly of individuals who have lost weight rapidly, are loose and relatively inelastic. It is reasonable to suppose that due to a 
similar change the intercellular spaces of the malnourished dogs may have lost some of their normal tension or ability to withstand distention with fluid. Such a change would account for the higher correlation levels observed in this group of animals. The explanation is presented only as an hypothesis based upon data which strongly suggest that the tissues of the malnourished dog are more easily distended with fluid than those of the relatively well-nourished dog whose plasma proteins have been depleted acutely by plasmapheresis. If the data obtained in dogs should turn out to be applicable in the human it may be noted that because in man low proteins are always associated with malnutrition, the correlation levels observed with such patients may not indicate accurately the full measure of protection which the normal individual possesses against the development of edema.

The preceding paragraphs have been written in full recognition of the fact that the phenomenon of edema is complicated. No mention has been made of the action of inorganic salts, diuretics, shifts in acid-base balance, etc., in modifying the degree of a previously existing edema although the influence of such factors is commonly observed in many large clinics. It may also have been noted that the conception of a constant equilibrium among the forces which control fluid distribution applies more closely in the case of nutritional than plasmapheresis edema. This, we believe, is due to the fact that fewer significant variables were introduced in the simple dietary experiments. Several observations in this group have indicated that the events following sudden changes in the quantity of ingested sodium chloride or after the addition of sodium bicarbonate to the dietary are complicated by additional and as yet obscure factors. In the experiments reported neither the quantity nor the composition of the salt mixture was changed during the periods under discussion. With the animals treated by plasmapheresis there is reason to believe that the sudden disturbance in equilibrium produced by the operative procedure introduced another factor, perhaps analogous to that following sudden shifts in dietary salt, which complicated the process of edema formation. In terms of the theory outlined one would expect a definite relation at all times between the degree of plasma protein depletion and the quantity of accumulated interstitial fluid. This quantitative relationship was not realized during periods of active plasmapheresis. Rather the impression was gained that, a tendency to fluid retention having been produced by sudden lowering of the plasma protein, the amount retained depended not only on the degree of the depletion but also on the quantity of salt and water ingested. The diets fed during these periods contained relatively large amounts of salt and it seemed that the gains in weight resulting from single plasmapheresis operations were frequently out of proportion to the degree of protein depletion. At least it was true that when the quantity of 
retained fluid had been multiplied by a number of successive operations, cessation of bleeding frequently resulted in prompt diuresis even though the plasma protein level was then lower than that which earlier had been associated with fluid retention. Such a sequence of events has been illustrated in Chart 1 . Therefore, although the experiments with plasmapheresis often revealed retention of fluid when the plasma albumin was considerably above the correlation level, nevertheless they did not furnish the same evidence of the existence of an equilibrium of forces as was secured in the experiments with nutritional edema. That a full understanding of the multiplicity of factors concerned in regulating movement and ultimate distribution of body fluids has not been attained, is attested not only by careful scrutiny of the findings in plasmapheresis but is also evident from frequent happenings in the clinic when edema suddenly recedes either as a result of empiric therapy or sometimes for no understandable reason at all.

\section{CONCLUSIONS}

1. Edema may be produced in dogs either by repeated plasmapheresis or maintenance on a diet deficient in protein.

2. The events preceding the onset of edema in both groups of animals fail to indicate the existence of a "margin of safety" in the plasma oncotic pressure which must be exceeded before retention of salt and water begins. The conclusion is based upon the behavior of weight curves and their relation to declining plasma proteins and the development of palpable edema. It is corroborated by studies of sodium, chloride, and nitrogen balance. The data argue in favor of gradual fluid retention which seems to accompany the entire process of plasma protein depletion.

3. When edema is looked upon as a degree of interstitial fluid accumulation great enough to permit detection by finger palpation, a fairly close correlation is found between this symptom and plasma albumin only. With concentrations less than 1 gram per $100 \mathrm{cc}$. edema is always present; with concentrations above 2 grams per $100 \mathrm{cc}$. it is nearly always absent.

4. The correlation levels in plasmapheresis and nutritional edemas are not identical. With plasmapheresis edema the level is $1.0-1.5$ gram per $100 \mathrm{cc}$. and with nutritional edema approximately 1.5-2.0 grams per $100 \mathrm{cc}$.

5. The subcutaneous edema fluid from dogs with nutritional edema contains in most instances between 0.10 and 0.35 gram protein per $100 \mathrm{cc}$. The average amount is slightly greater than that reported by Leiter in plasmapheresis edema but there is some overlapping in the results of individual analyses.

6. Plasma specific gravity follows closely the fluctuations in total plasma protein and does not exhibit a correlation with edema. 
7. The manner in which edema develops, namely, by successive increments of fluid retained over a time which seems to embrace the entire period of plasma albumin depletion, suggests the presence of an equilibrium between plasma proteins and the volume of fluid in the interstitial spaces. The equilibrium is conceived to be the result of a balance between forces which exist on both sides of the capillary wall.

8. As an explanation of the different correlation levels in nutritional and plasmapheresis edemas, it is suggested on hypothetical grounds that the interstitial spaces of the malnourished animal may lose some of their elasticity or ability to withstand distention as a result of the malnutrition and, therefore, more readily fill with edema fluid.

9. It is believed that the sudden disturbance in equilibrium produced by the operation of plasmapheresis introduces an obscure factor in the process of edema formation which is not present in animals whose plasma proteins are depleted by diet alone.

\section{BIBLIOGRAPHY}

1. Leiter, L., Medicine, 1931, x, 135. Nephrosis.

2. Peters, J. P., and Van Slyke, D. D., Quantitative Clinical Chemistry. Volume I. Interpretations. Chapter XIII. Proteins of the Urine, Blood Plasma, and Other Body Fluids. Williams and Wilkins Co., Baltimore, 1931, p. 653.

3. Krogh, A., The Anatomy and Physiology of Capillaries. New Haven, 1929, 2d ed.

4. Fishberg, A. M., Hypertension and Nephritis. Lea and Febiger, Philadelphia, 1931, 2d ed.

5. Weech, A. A., and Ling, S. M., J. Clin. Invest., 1931, x, 869. Nutritional Edema. Observations on the Relation of the Serum Proteins to the Occurrence of Edema and to the Effect of Certain Inorganic Salts.

6. Leiter, L., Proc. Soc. Exper. Biol. and Med., 1928, xxvi, 173. Experimental Edema.

Idem, 1930, xxvii, 1002. Experimental Edema. Further Observations on the Plasma Proteins and Blood Cholesterol.

Arch. Int. Med., 1931, xlviii, 1. Experimental Nephrotic Edema.

7. Barker, M. H., and Kirk, E. J., Arch. Int. Med., 1930, xlv, 319. Experimental Edema (Nephrosis) in Dogs in Relation to Edema of Renal Origin in Patients.

8. Shelburne, S. A., and Egloff, W. C., Arch. Int. Med., 1931, xlviii, 51. Experimental Edema.

9. Lepore, M. J., Proc. Soc. Exper. Biol. and Med., 1931, xxix, 318. Experimental Edema Produced by Plasma Protein Depletion.

10. Fahr, G., Kerkhof, A., and Giere, E., Proc. Soc. Exper. Biol. and Med., 1931, xxix, 335. Salt as a Factor in Edema Formation Following Plasmaphoresis.

11. Darrow, D. C., Hopper, E. B., and Cary, M. K., J. Clin. Invest., 1932, xi, 683. Plasmapheresis Edema. I. The Relation of Reduction of Serum Proteins to Edema and the Pathological Anatomy Accompanying Plasmapheresis. 
12. Frisch, R. A., Mendel, L. B., and Peters, J. P., J. Biol. Chem., 1929, lxxxiv, 167. The Production of Edema and Serum Protein Deficiency in White Rats by Low Protein Diets.

13. Koch, F. C., and McMeekin, T. L., J. Am. Chem. Soc., 1924, xlvi, 2066. A New Direct Nesslerization Micro-Kjeldahl Method and a Modification of the Nessler-Folin Reagent for Ammonia.

14. Howe, P. E., J. Biol. Chem., 1921, xlix, 109. The Determination of Proteins in Blood-A Micro Method.

15. Bruckman, F. S., D’Esopo, L. M., and Peters, J. P., J. Clin. Invest., 1930, viii, 577. The Plasma Proteins in Relation to Blood Hydration. IV. Malnutrition and the Serum Proteins.

16. Atchley, D. W., and Loeb, R. F., Personal communications.

17. Butler, A. M., and Tuthill, E., J. Biol. Chem., 1931, xciii, 171. An Application of the Uranyl Zinc Acetate Method for Determination of Sodium in Biological Material.

18. As given by Hawk, P. B., and Bergeim O., Practical Physiological Chemistry. 1926, 9th ed., P. Blakiston \& Son, Philadelphia.

19. Moore, N. S., and Van Slyke, D. D., J. Clin. Invest., 1930, viii, 337. The Relationships between Plasma Specific Gravity, Plasma Protein Content and Edema in Nephritis.

20. Smith, H. P., Belt, A. E., and Whipple, G. H., Am. J. Physiol., 1920, lii, 54. I. Rapid Blood Protein Depletion and the Curve of Regeneration.

21. Bürger, M., Ergebn. d. inn. Med. u. Kinderh., 1920, xviii, 189. Die Ödemkrankheit.

22. Maver, M. B., J. A. M. A., 1920, lxxiv, 934. Nutritional Edema and "War Dropsy."

23. Denton, M. C., and Kohman, E., J. Biol. Chem., 1918, xxxvi, 249 . Feeding Experiments with Raw and Boiled Carrots.

24. Kohman, E. A., Am. J. Physiol., 1920, li, 378. The Experimental Production of Edema as Related to Protein Deficiency.

25. Gamble, J. L., Putnam, M. C., and McKhann, C. F., Am. J. Physiol., 1929, lxxxviii, 571. The Optimal Water Requirement in Renal Function. I. Measurements of Water Drinking by Rats According to Increments of Urea and of Several Salts in the Food.

26. Wheeler, G. A., Goldberger, J., and Blackstock, M. R., U. S. Pub. Health Rep., 1922, xxxvii, 1063. On the Probable Identity of the ChittendenUnderhill Pellagralike Syndrome in Dogs and "Blacktongue."

27. Starling, E. H., J. Physiol., 1896, xix, 312. On the Absorption of Fluids from the Connective Tissue Spaces.

28. Krogh, A., Landis, E. M., and Turner, A. H., J. Clin. Invest., 1932, xi, 63. The Movement of Fluid through the Human Capillary Wall in Relation to Venous Pressure and to the Colloid Osmotic Pressure of the Blood.

29. Landerer, A., Die Gewebsspannung in ihrem Einfluss auf die örtliche Blutund Lymphbewegung. Leipzig, 1884.

30. Schade, H., Ergebn. d. inn. Med. u. Kinderh., 1927, xxxii, 425. Über Quellungsphysiologie und Odementstehung.

31. Field, M. E., and Drinker, C. K., Am. J. Physiol., 1931, xcvii, 40. The Permeability of the Capillaries of the Dog to Protein.

32. Iversen, P., and Johansen, E. H., Klin. Wchnschr., 1929, viii, $309 . \quad$ Pathogenese und Resorption von Trans- und Exsudaten in der Pleura (Salyrganwirkung).

33. Field, M. E., and Drinker, C. K., Am. J. Physiol., 1931, xcviii, 378. The Rapidity of Interchanges between the Blood and Lymph in the Dog. 